DOI: 10.19085/journal.sijmd030101

\title{
J M Keynes on the Definition of Uncertainty: Why Uncertainty must come in Degrees and has nothing to do with Ergodicity or Non Ergodicity
}

\author{
Michael Emmett Brady \\ Lecturer, \\ School of Business Administration and Public Policy \\ Department of Operations Management \\ California State University, Dominguez Hills \\ Victoria Street \\ Carson, California \\ USA.
}

oScholedge International Journal of Management \& Development (ISSN 2394-3378), Vol.03, Issue 01 (2016) pg1-10.

Published by: Scholedge R\&D Center [www.theSCHOLEDGE.org] [Email: sijmd@scholedge.org]

\begin{abstract}
Keynes's definition of uncertainty is directly based on his weight of the argument (evidence) relation, analyzed in chapters 6 and 26 of the A Treatise on Probability (1921), page 148,as well as the footnote on page 148 ,of the General Theory (1936) ,and multiple pages of his February, 1937 Quarterly Journal of Economics article. There is no discussion of the definition of Uncertainty in his exchanges with Jan Tinbergen in 1939-40 in the Economic Journal.

Paul Davidson and his Post Keynesian-Institutionalist supporters base their Ergodic-Non Ergodic approach to the definitions of uncertainty and risk on the inductive fallacy of Conditional A priorism (Long Runism).The claim , made by Paul Davidson and his Post Keynesian-Institutionalist supporters for over 30 years, that decision makers are able to identify the ergodicity or non ergodicity of long run stochastic sequences or series of events or outcomes in the short run ,based on Davidson's claim that decision makers are able to know or learn of the convergence properties of such series or sequences, which can only be known "in the long run "(infinity), by examining sub series or sub sequences, is patently false and not accepted by any scholar in any other academic field .

Davidson bases his binary approach to uncertainty, which rules out any concept of different degrees to knowledge (certainty) and unknowledge (uncertainty), on both metaphysical speculations and/or a priori claims to knowledge. There can be no such thing as probable knowledge under this binary approach.
\end{abstract}

Keywords: Economic theory, economics, practice of economics, JM Keynes.

\section{Section 1.) Introduction}

This paper will examine the logically flawed nature of the Paul Davidson-Post Keynesian claim that real world decision makers are able to examine small sub sequences or sub series of the entire infinite sequence or series of a stochastic process over time and determine whether the infinite sequence or series is ergodic or non ergodic. Uncertainty is then defined in terms of Non Ergodicity. 
We will have to examine the work of philosophers like Charles Sanders Peirce, Hans Riechenbach, and Nicholas Rescher in order to be able to come to a conclusion about this claim. We will then examine the writings of Paul Davidson and show where fallacies occur that falsify his claims.

We will conclude that the Paul Davidson -Post Keynesian-Institutionalist claim that decision makers are able to determine the long run (infinite) behavior of stochastic series of events or outcomes based on their examination of specific samples in the short run has no basis or support in any field of logic or science.

Section 2 will examine Keynes's very clear cut definition of uncertainty based on his General Theory $(1936 ; G T)$ and February ,1937 Quarterly Journal of Economics article. Section 3 covers the fallacy of Conditional Apriorism (Long Runism) in depth and explains why it must fail .Section 4 examines a number of specific claims published by Davidson and shows how they are either a priori claims to knowledge or purely metaphysical speculations. Section 5 analyzes how another Post Keynesian, A. Terzi, falls into the fallacy of long runism by basing her analysis of uncertainty on P. Davidson's antiKeynes ,binary, definition of uncertainty passes down to Davidson from G L S Shackle. Section 6 concludes that the Post Keynesians are in direct conflict with $J \mathrm{M}$ Keynes over the definition of uncertainty and the concept of degrees of uncertainty .

\section{Section 2.) The Definition of Uncertainty of J M Keynes}

Keynes very carefully defined uncertainty in the General Theory $(G T ; 1936)$ in the following way:

"It would be foolish, in forming our expectations, to attach great weight to matters which are very uncertain [1]. It is reasonable, therefore, to be guided to a considerable degree by the facts about which we feel somewhat confident, even though they may be less decisively relevant to the issue than other facts about which our knowledge is vague and scanty. For this reason the facts of the existing situation enter, in a sense disproportionately, into the formation of our long-term expectations; our usual practice being to take the existing situation and to project it into the future, modified only to the extent that we have more or less definite reasons for expecting a change.

The state of long-term expectation, upon which our decisions are based, does not solely depend, therefore, on the most probable forecast we can make. It also depends on the confidence with which we make this forecast-on how highly we rate the likelihood of our best forecast turning out quite wrong..."(Keynes,GT, pp.148)

The footnote [1] above that was attached by Keynes to this quotation is extremely important and has been ignored by Shackle and Davidson over the course of their academic careers:

“1. By "very uncertain' I do not mean the same thing as "improbable". Cf. my Treatise on Probability, chap. 6, on "The Weight of Arguments". (Keynes, p.148 )

Therefore, uncertainty and weight are related according to Keynes. How are they related? Keynes has already given the answer:

"It would be foolish, in forming our expectations, to attach great weight to matters which are very uncertain [1]"

Therefore, low weight must be attached to matters which are very or highly or greatly uncertain. An inverse relationship has been specified by Keynes to exist between uncertainty and weight. High uncertainty means that there is low weight and low uncertainty means that there is high weight.Note that Keynes has already defined uncertainty as coming in degrees on this page. 
Thus, there is a negative relationship between Uncertainty $(U)$ and weight $(W)$.This relationship was more fully developed by Keynes in Chapter 26 of the TP, which completed the discussion of topics that began in chapter 6 of the TP. Keynes incorporated $w$ into the world's first nonlinear, non-additive decision rule, his c coefficient, which comes in different degrees. F Y Edgeworth realized that Keynes had made a major breakthrough in decision theory. However, Edgeworth was unable to figure it out for himself.He asked the Readers of Mind (1922) for help, but received none. Edgeworth's death in 1925 resulted in Keynes's c coefficient simply disappearing from sight in academic literature in the 20th century.

Given that "It would be foolish... to attach great weight to matters which are very uncertain [1]", one should attach little weight to matters which are very uncertain and great weight to matters which are relatively certain. The following relationship holds. If $w$ increases, then $U$ decreases while if $w$ decreases, then $U$ increases. Weight is a function of the total, relevant evidence .The total, relevant, evidence is that evidence which is reliable and available, plus any evidence that has a bearing on the decision, but which is currently missing or unavailable in either the present or future.

Nowhere in any of either Davidson's or Shackle's scholarly, academic writings over a 50 plus year period of time will a reader find any mention of Keynes's two footnotes (Keynes,GT,p.142,p.240 ) explicitly defining uncertainty in terms of the weight of the argument (evidence) from the TP. This is because Keynes's definition of uncertainty in terms of weight directly contradicts and refutes both Shackle's and Davidson's claims concerning both the meaning of the term uncertainty or how Keynes defined and applied his concept of uncertainty in the GT.Davidson's own definition, taken from Shackle ,directly conflicts with Keynes's definition

We now turn to Keynes's 1937, February, QJE article.

Our second concern is whether uncertainty comes in different degrees and gradations. This is only possible if uncertainty is epistemological. It is impossible to have different degrees of ergodicity or non ergodicity, although you can have weak and strong forms of either ergodicity or non ergodicity.No Post Keynesian or Institutional economist has ever considered the internal conflict in accepting that uncertainty comes in different degrees and that uncertainty must be defined in terms of non ergodicity.

Keynes is very clear:

"By "uncertain" knowledge, let me explain, I do not mean merely to distinguish what is known for certain from what is only probable. The game of roulette is not subject, in this sense, to uncertainty; nor is the prospect of a Victory bond being drawn. Or, again, the expectation of life is only slightly uncertain. Even the weather is only moderately uncertain. The sense in which I am using the term is that in which the prospect of a European war is uncertain, or the price of copper and the rate of interest twenty years hence, or the obsolescence of a new invention, or the position of private wealthowners in the social system in 1970. About these matters there is no scientific basis on which to form any calculable probability whatever. We simply do not know. Nevertheless, the necessity for action and for decision compels us as practical men to do our best to overlook this awkward fact and to behave exactly as we should if we had behind us a good Benthamite calculation of a series of prospective advantages and disadvantages, each multiplied by its appropriate probability, waiting to be summed."(Keynes,1937,pp.213-214)

and

"Because, partly on reasonable and partly on instinctive grounds, our desire to hold Money as a store of wealth is a barometer of the degree of our distrust of our own calculations and conventions concerning the future. (Author's underline). Even though this feeling about Money is itself conventional or instinctive, it operates, so to speak, at a deeper level of our motivation. It takes charge at the moments when the higher, more precarious conventions have weakened. The possession of 
actual money lulls our disquietude; and the premium which we require to make us part with money is the measure of the degree of our disquietude.(Author's underline).The significance of this characteristic of money has usually been overlooked; and in so far as it has been noticed, the essential nature of the phenomenon has been misdescribed. For what has attracted attention has been the quantity of money which has been hoarded; and importance has been attached to this because it has been supposed to have a direct proportionate effect on the price-level through affecting the velocity of circulation. But the quantity of hoards can only be altered either if the total quantity of money is changed or if the quantity of current money-income (I speak broadly) is changed; whereas fluctuations in the degree of confidence (Author's underline) are capable of having quite a different effect, namely, in modifying not the amount that is actually hoarded, but the amount of the premium which has to be offered to induce people not to hoard." (Keynes,1937,p.216).

It is mathematically and logically impossible for confidence to come in degrees, for trust to come in degrees and for the liquidity premium to be a measure of the degree of our disquietude and uncertainty not to come in degrees because confidence is an inverse function of uncertainty given Keynes's clear definition of uncertainty as an inverse function of the weight of the evidence on p.148 and p.240 of the GT .Thus, as uncertainty increases, confidence decreases and as uncertainty decreases ,confidence increases. It is impossible for this relation to hold if uncertainty can't come in degrees. Given that ergodicity and non ergodicity can't come in different degrees, it is impossible for a decision maker to define uncertainty in terms of non ergodicity. Only a binary relation, with no degrees is logically possible.

An example of the erroneous beliefs that Post Keynesians have about Keynes's degree of uncertainty can be found in the following exchange between John Harvey, a leading Post Keynesian/Institutionalist economist and Editor of the World Economic Review, and the author of a submitted paper ,Angelo Fusari, on November 26,2012. Harvey makes the following claim:

"I still maintain that fundamental uncertainty is binary: either it exists or it does not.l consulted a number of Keynes scholars on this point and the response was unanimous... the burden is on the one trying to prove that degrees exist".( http://werdiscussion.worldeconomicsassociation.org/?post=radical-uncertainty-dynamic-co...)

The claim made by Harvey that"... fundamental uncertainty is binary: either it exists or it does not.", is the Shackle-Davidson-claim that Keynes rejected.

The binary view of Shackle, Davidson and Post Keynesians, in general, is recognized as being, not only erroneous, but dangerous:

"One danger is that this traditional approach leads executives to view uncertainty in a binary way-to assume that the world is either certain, and therefore open to precise predictions about the future, or uncertain, and therefore completely unpredictable. Planning or capital-budgeting processes that require point forecasts force managers to bury underlying uncertainties in their cash flows. Such systems clearly push managers to underestimate uncertainty in order to make a compelling case for their strategy."(Courtney,Kirkland,and Viguerie,1997,p.2;see also Courtney,Kirkland,and Viguerie,2000)

Keynes's index of the weight of evidence, used by Keynes to define uncertainty in terms of weight in the GT, is very clearly defined and applied on p.148 and p.240 of the GT .See the discussion above. For Keynes, degrees of uncertainty exist. Not so for Post Keynesians.

Only in the case of complete and total ignorance would there be no degrees of uncertainty. Such an extreme case is defined by Keynes in the A Treatise on Probability (1921)in chapter 26, p.314,ft.2, to be a situation where $w$, the weight of the evidence, equals 0 . 
Harvey and his "Keynes scholars " are in direct conflict with Keynes's approach to uncertainty .Harvey's approach has nothing to do with Keynes's. He has restated the Shackle-Davidson position that knowledge means certainty, so unknowledge means uncertainty. This binary approach ,as discussed above ,was rejected by Keynes. There is no such thing as Keynes's probabilistic knowledge for the Post Keynesians. Harvey and his " Keynes scholars "are arguing for Shackle's position, not Keynes's, which was that if knowledge exists, which must be certain, then there can be no uncertainty. But if uncertainty exists, there can be no knowledge:

Davidson restates Shackle 's position: "Once technical definitions of the concept of uncertainty and its inverse, knowledge , ..." and "knowledge's inverse, the concept of uncertainty..." (Davidson,1987, p. 147).

\section{Section 3.) The Fallacy of Conditional Apriorism (Long Runism)}

Davidson's claim that decision makers can identify whether or not specific ,stochastic series are ergodic or non ergodic rests on the earlier, erroneous claims made by Pierce and Reichenbach.

Davidson's claim is that decision makers can differentiate in the short run between stochastic processes that are ergodic or non ergodic, although the ergodicity or non ergodicity of any infinite series or sequence of observations will only occur in the long run.

Davidson's error is a direct result of his reliance on the limiting -frequency interpretation of probability. Davidson claims that the infinite or indefinite series of observations can be analyzed in the short run so that a decision maker could identify either a long run state of convergence/non convergence/divergence to/from a stable limiting point around which cluster random error terms which cancel out in the long run. This, of course, is an a priori claim about whether or not a limit exists to the series of observations in the long run.

"The root problem of the Peirce-Reichenbach approach is that two rather different gaps need to be closed...

(1)The potential gap between "the frequency indicated by the data in hand ( $\Theta t$.$) " and "the ultimate$ frequency in observation", $\lim (\Theta t$ ) as $t$ approaches $\infty$ and

(2)The potential gap between "the frequency in observation ", $\lim (\Theta t)$ as $t$ approaches $\infty$ "and "the frequency in Nature $(\Theta)$ ”. (Rescher,1980,p.104).

Davidson's claim only deals with the first gap, that the first gap is or is not closed in the limit or in the long run.

Davidson closes these gaps by simply asserting that decision makers can know the nature of the limiting behavior of the infinite series in the short run. This is the fallacy of conditional a priorism because Davidson conditions his claims on a priori claims made about the capacity of decision makers to recognize that the series are non convergent or divergent in the short run:

"...the long run behavior of such a limit function is compatible with any short run behavior whatsoever. There is no reason to regard the ratio, with $\Theta t$, with $t=N O W$, as foreshadowing or approximating the actual(long term)probability .For no value of $t$, no matter how large, does $\Theta t$ bear any determinate relationship to the ultimate limit value-unless we are prepared to postulate a priori knowledge about the nature of the world...".(Rescher,1980,pp.101-102). 


\section{Section 4.) Some examples of Davidson's Metaphysical Speculations and A priori Claims to Knowledge}

Consider the following two claims made by Davidson. We will examine them one by one and show that they involve metaphysical speculation and /or a priori claims to knowledge. There are dozens of similar examples that could be used from Davidson's past works. Claim one is that:

"In the real world, some economic processes may be ergodic, at least for short sub-periods of calendar time, while others are not. The problem facing every decision maker is to guess whether (1) the phenomena involved are currently being governed by probability distribution functions which are sufficiently time invariant as to be presumed ergodic - at least for the relevant future ... or (2) non-ergodic circumstances are involved.

(Davidson, 1989, p. 14, underline added; see also 1996, p. 501).

The claim that "... at least for short sub-periods of calendar time" is pure metaphysical speculation on Davidson's part. This can only be known in the long run and fails to satisfy Rescher's points (1) and (2) above.

The claim that "The problem facing every decision maker is to guess" is pure metaphysical speculation on Davidson's part. Guessing has nothing to do with learning, which can only be known in the long run and fails to satisfy Rescher's points (1) and (2) above.

The claim that "... are sufficiently time invariant " are nothing more than a priori claims with no support .

The claim that "... to be presumed ergodic" " is nothing more than an a priori claim with no support .

The claim that "... at least for the relevant future ..." is pure metaphysical speculation on Davidson's part. Guessing has nothing to do with learning which can only be known in the long run and fails to satisfy Rescher's points (1) and (2) above.

Consider the following piece of analysis by Davidson:

"In the short run, agents can rightly or wrongly believe that A is ergodic, $B$ is nonergodic, or even that $C$ is ergodic sometimes and nonergodic at other times. Only the future will tell whether any or all of these beliefs are correct." (Davidson, 1993, p. 432).

The claim that "In the short run, agents can rightly or wrongly believe that A is ergodic, $B$ is nonergodic, ...." is pure metaphysical speculation on the part of such agents combined with a priori claims on the part of the decision maker that he "knows" the actual limit as t approaches $\infty$. Davidson's argument postulates knowledge of the limiting behavior of the entire sequence that will only occur when t equals infinity .

The claim that "... or even that $C$ is ergodic sometimes and nonergodic at

other times." could only hold on a priori grounds for some of the many sub sequences that are temporarily in a state of non convergence or divergence in the ergodic state or that are temporarily converging for a sub sequences of the entire sequence in the non ergodic state. The limit when $t$ equals infinity will be either ergodic or non ergodic.

The claim that "... Only the future will tell whether any or all of these beliefs are correct." can only occur when both of Rescher's conditions hold. 


\section{Section 5.) Terzi's Metaphysical Speculations about J M Keynes's approach to Uncertainty}

Consider the following claim made about Keynes's approach to uncertainty by Terzi:

"Conversely, models assuming ontological uncertainty admit that agents know they live in a constantly changing environment where the future is not predetermined by the past and that no apparent regularity can be considered a permanently acquired basis for a statistical anticipation of the future. Although agents have no option other than using the past as their only source of knowledge, they know that non predetermined surprises are possible. These models are equipped to describe agents' behavior under uncertainty and explain their demand for protection from surprises.

This is Keynes's approach...".(Terzi,2010,p.562)

No. Terzi's statement above is not Keynes's approach. Keynes's approach is based on epistemological uncertainty and not any metaphysical and/ or apriori claims about knowing the ultimate nature of reality. It follows directly from chapters 6 and 26 of the A Treatise on Probability where Keynes defined his completeness of the relevant knowledge coefficient, w, where $w$ is defined and normalized on the unit interval [0,1].Keynes, following Boole,analyzed determinate probabilities (risk) and indeterminate probabilities(uncertainty,ignorance) .Uncertainty is defined in chapter 12 on p. 148 in the General Theory $(G T ; 1936)$ as an inverse function of weight. How "... agents know they live in a constantly changing environment where the future is not predetermined by the past..." and how "...they know that non predetermined surprises are possible" is never explained by Terzi. This certainly does not apply to the consumption goods sector of the economy where analysis and future projections are usually correct due to the fact that consumption goods preferences change very, very slowly overtime. Similarly, businessmen, dealing with inventory investments, which mirror consumption patterns,are able to forecast changes in inventories. Consumption spending is fairly stable and predictable over time, given that the relatively stable consumption preferences of consumers change very slowly for $99 \%$ of consumption products over time.

Consider the following statement by Terzi:

"A central element in Keynes's theory is the assumption that economic agents know they live in an uncertain environment."

This is only correct if uncertainty is defined as a set of different uncertain states ranging from completely uncertain at one extreme through acute uncertainty to moderate uncertainty to mild uncertainty to a small degree of uncertainty to complete certainty at the other extreme.

The claim that "economic agents know they live in an uncertain environment." can't be derived from the long run limiting behavior of either ergodic or non-ergodic series of outcomes since no one has the capability to derive that knowledge.

Finally, consider the following :

"Although the system is ergodic, 5 we cannot forecast it well because known past observations provide us with a sample too small to quantify the probability

of extremely rare events. Such outliers can blow up an invested portfolio or an entire banking system. Agents believe they can decipher

the future when in fact they do not have this capability."(Terzi,2010,p.563)

In fact, it is not possible to forecast it at all. Only in the far distant long run, as infinity is approached ,will convergence appear for ergodic series. 
The Davidson /Post Keynesian claim that "learning from experience"(see Davidson,1993p.425;1994,pp.88-89;2011,pp.99-100) will eventually convert epistemological uncertainty into neoclassical probabilistic risk means that Davidson and the Post Keynesians never understood what Keynes was talking about in the TP.Boole made it crystal clear that indeterminate probabilities would not become determinate probabilities over time because there is permanently missing information or evidence that will never be gained .Constant technological advance ,change and innovation, combined with the equally severe problem of technological obsolescence, means that businessmen can never "learn from experience" about the next breakthrough that will threaten their investments in their fixed, long lived, durable, capital goods .Davidson's claims about epistemological uncertainty converging to risk makes no sense .

\section{Section 6.) Conclusions}

Post Keynesian views on the definition and application of the concept of uncertainty is a mass of conflicting , metaphysical speculations ,a priori claims to knowledge, and definitional confusions best illustrated by the myriad errors that permeate the Post Keynesian understanding of Keynes's concept of uncertainty. Note that it is not possible to logically hold that uncertainty comes in degrees and at the same time hold that Davidson's definition of uncertainty is correctly based on the concept of non ergodicity. There is no such thing as the degree of non ergodicity. At least Davidson is consistent in his error.

The Post Keynesian view of acting in the face of uncertainty is a binary one.There is either certainty or there is uncertainty. There is knowledge or there is no knowledge(Shackle's unknowledge).How these vague, unclear, inapplicable, and dubious assertions came to represent the definition and meaning of uncertainty for Post Keynesians is unclear. What is clear is that these Post Keynesian views have absolutely nothing to do with anything written or spoken by $J$ M Keynes in his lifetime.

\section{References}

Boole, George. 1958 [1854]. An Investigation of the Laws of Thought on Which are Founded the Mathematical Theories of Logic and Probability. New York: Dover Publications.

Brady, Michael Emmett. (1983).The Foundation of Keynes' Macroeconomics: His Logical Theory of Probability and its Application in The General Theory and after. Unpublished Dissertation, University of California, Riverside, July, 1983.

Brady, Michael Emmett. (1986).A Note on Milton Friedman's Application of His "Methodology of Positive Economics". Journal of Economic Issues. Vol. 20, No. 3 (Sept., 1986), pp. 845-851.

http://dx.doi.org/10.1080/00213624.1986.11504549

Brady, Michael Emmett. (2015). On J M Keynes's Rejection of the Moscow School of Probability's Limiting Frequency Approach to Probability and Kolmogorov's Axiom of Additivity (Countable Additivity ): Non -Additivity was the fundamental, basic axiom upon which all of the Economics of Keynes was Built. Scholedge International Journal of Management \& Development (ISSN 2394-3378), Vol.02, Issue 11, (2015), pp.7-20.

http://dx.doi.org/10.19085/journal.sijmd021102 
Courtney, H, Kirkland, J., and Viguerie, P. (1997).Strategy under Uncertainty. Harvard Business Review, (November-December) Vol. 75, Issue 6, pp. 67-79.

Courtney, H, Kirkland, J., and Viguerie, P. (2000).Strategy under Uncertainty.McKinsey Quarterly, (June), pp.1-6. www.mckinsey.com/...uncertainty/strategy under...

Davidson, P. (1987).Sensible Expectations and the Long Run non-Neutrality of Money. Journal of Post Keynesian Economics, vol. 10, pp.146-153

http://dx.doi.org/10.1080/01603477.1987.11489666

Davidson, P. (1993). "Austrians and Post Keynesians on Economic Reality: Rejoinder to Critics. "Critical Review, 1993, 7 (2-3), 423-444.

http://dx.doi.org/10.1080/08913819308443309

Davidson, P. (1994). Post Keynesian Macroeconomic Theory. Aldershot, UK: Edward Elgar. http://dx.doi.org/10.1080/01603477.1994.11490022

Davidson, P. (1996). "Reality and Economic Theory." Journal of Post Keynesian Economics, 18 (4), 479-508. http://dx.doi.org/10.1080/01603477.1996.11490083

Davidson, P. (2010). "Black Swans and Knight's Epistemological Uncertainty." Journal of Post Keynesian Economics, 2010, 32 (4), 567-570.

http://dx.doi.org/10.2753/PKE0160-3477320404

Davidson, P. (2011). Post Keynesian Macroeconomic Theory, 2nd ed. Cheltenham, UK: Edward Elgar, 2011.

Davidson, P. (2012). "Is Economics a Science? Should Economics Be Rigorous?" Real World Economics Review, 2012, 59.

Fusari, Angelo -Harvey, John .Comments. (11-26-2012).

(http://werdiscussion.worldeconomicsassociation.org/?post=radical-uncertainty-dynamic-com...) 
Keynes,J M .(1921).A Treatise on Probability. England: Macmillan and Company

Keynes, J. M. (1936). The General Theory of Employment ,Interest and Money. New York, Prometheus Books,1997.

Keynes,J. M. (1937).The General Theory of Employment, Quarterly Journal of Economics,51.1,209-223. http://dx.doi.org/10.2307/1882087

Keynes, J. M.(1939).Book Review-Professor Tingergen's Method.

The Economic Journal, Vol. 49, No. 195. (Sep., 1939), pp. 558-577.

Rescher, Nicholas. (2014).Peirce's Epistemic Eschatology.2014 Charles S. Peirce International Centennial Congress. U Mass; Lowell, Massachusetts (Friday, July 18).

Rescher, Nicholas. (1978a). "Peirce and the Economy of Research." In Peirce's Philosophy of Science. Indiana: University of Notre Dame Press.

Rescher, Nicholas. (1978b). Scientific Progress. Pittsburgh: University of Pittsburgh Press.

Rescher, Nicholas. (1980a). Induction. Oxford: Basil-Blackwell.

Rescher, Nicholas. (1980b). Unpopular Essays on Technological Progress. University of Pittsburgh Press.

Terzi, A. (2010). "Keynes's uncertainty is not about white or black swans". Journal of Post Keynesian Economics.Vol. 32.no.4pp.559-565.

http://dx.doi.org/10.2753/PKE0160-3477320403 